\title{
Kenntnisse im Strahlenschutz bequem von zu Hause aus aktualisieren
}

Ihre Fachkunde muss noch schnell in diesem Jahr aktualisiert werden? Keine Sorge - Sie können das im Handumdrehen erledigen: mit dem „Fachkunde-Kombipaket Online- und Präsenzkurs“ der DRG. Besuchen Sie unser Onlinemodul (A) am 5. oder 29. September 2016, und suchen Sie sich ein passendes Präsenzmodul (C) aus (Oktober in Köln oder Dezember in Fürth / Nürnberg). Mit dem Besuch der Module A (Online) und B (Präsenz) und / oder C (Präsenz) und dem Ablegen aller erforderlichen Prüfungen beim Präsenzteil haben Sie Ihre Fachkunde nach Röntgen- und/oder Strahlenverordnung aktualisiert.

Alle Informationen und Ihren persönlichen Ansprechpartner für alle Fragen rund um die Fachkundeaktualisierung finden Sie hier: drgakademie.de > Akademie Online > Fachkundeaktualisierung

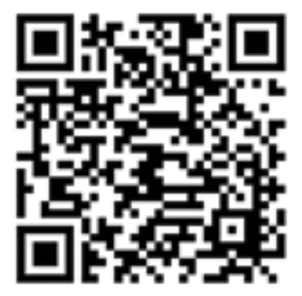

